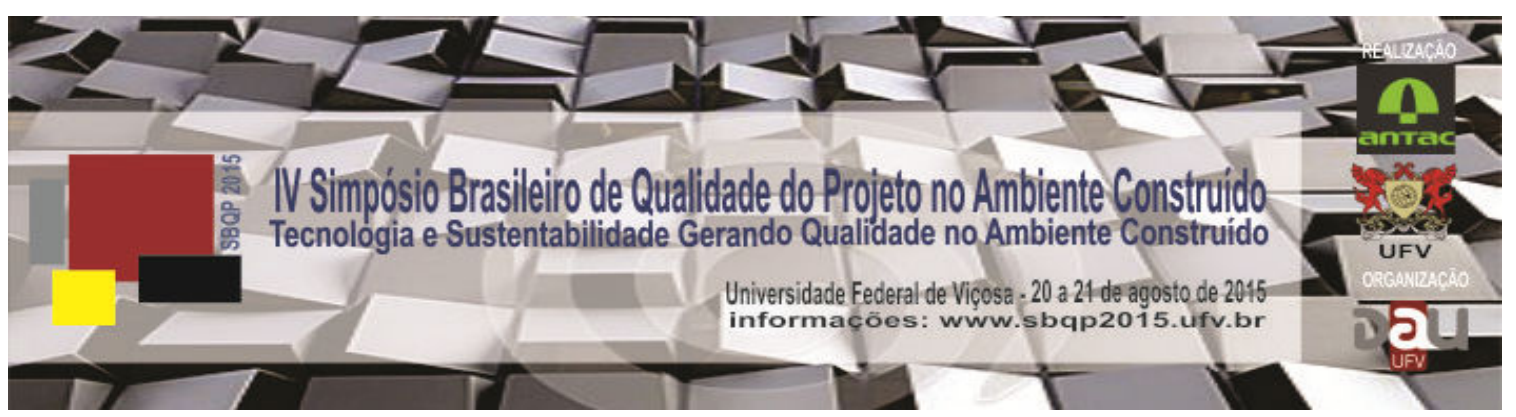

\title{
OS IMPACTOS DO PROCESSO DE PROJETO NA EXECUÇÃO E DESEMPENHO DA FACHADA 1
}

\author{
CARRARO, Marília \\ Instituto de Pesquisas Tecnológicas do Estado de São Paulo - IPT, \\ carraro.marilia@gmail.com \\ OLIVEIRA, Luciana Alves \\ Instituto de Pesquisas Tecnológicas do Estado de São Paulo - IPT, luciana@ipt.br
}

\begin{abstract}
RESUMO
O projeto na construção civil envolve cada vez mais especialidades, ao mesmo tempo em que exigências de prazo, custo e desempenho são maiores. A qualidade do projeto tem impacto no processo construtivo e nas etapas de uso e ocupação do edifício, influenciando o seu comportamento ao longo da vida útil. O objetivo deste artigo é analisar o processo de projeto e a execução do sistema de fachada de um edifício hospitalar. Para tanto, foram feitas pesquisas bibliográficas e um estudo de caso, no qual o projeto e a execução da fachada foram analisados. Assim, não conformidades foram identificadas durante a execução da fachada e suas causas e impactos quanto ao desempenho analisados. Estes problemas identificados muitas vezes interferem diretamente no processo construtivo, podendo persistir e ameaçar 0 desempenho da edificação. Observou-se que a maior parte das não conformidades levantadas tiveram suas origens em falhas do processo de projeto. E, portanto, poderiam ter seu impacto reduzido por um planejamento mais atento aos conflitos potenciais e um detalhamento mais cuidadoso do projeto.
\end{abstract}

Palavras-chave: Processo de projeto, Desempenho, Patologias, Fachada leve.

\begin{abstract}
The construction project increasingly involves different specialties while, at the same time, greater time demands, cost and performance requirements. The quality of the project impacts on the construction process and the building performance along its life cycle. A bibliographic research and a hospital building case study were made, in which the design process and execution of the façade were analyzed. So nonconformities were identified and its causes and impacts on the performance were studied. Most of these nonconformities result from design process failures. Thus they could have been mitigated by planning and through an awareness of possible problems as well as careful detailing of a given project.
\end{abstract}

Keywords: Design, Performance, Pathologies, Lightweight façade.

\footnotetext{
1 Trabalho apresentado no IV SBQP 2015. Universidade Federal de Viçosa. Disponível em: doi> http://dx.doi.org/10.18540/2176-4549.6056
} 


\section{INTRODUÇÃO}

O processo de projeto torna-se mais complexo na medida em que há mais especialidades e maior uso de processos e produtos industrializados. É durante o projeto que as principais questões relativas às exigências dos usuários, sejam técnicas, ambientais ou de custo, devem ser equacionadas; iniciando-se na fase de concepção.

De acordo com Beasley (2012), as patologias de fachada têm causas diversas, sendo que aquelas que progridem ao longo do tempo comprometendo o desempenho da fachada, normalmente, foram originadas em projeto. O autor destaca que isso pode ocorrer pela ausência de uma comunicação eficiente com a obra (BEASLEY, 2012). Ainda, ao analisar uma série de casos de falhas de engenharia, Williams Jr. e Johnson (2015) concluem que frequentemente as falhas são decorrentes de uma gestão inadequada do projeto e não de desafios técnicos.

Entendendo a importância do projeto para a qualidade da execução e para o desempenho do edifício, principalmente em sistemas complexos como a fachada, o objetivo deste artigo é analisar o processo de projeto e a execução da fachada de um edifício hospitalar, visando identificar a ocorrência de falhas no projeto e se essas impactaram no desempenho do edifício e na sua execução.

O desempenho é tratado neste artigo conforme conceito explicitado no conjunto de normas brasileiras de desempenho para edifícios habitacionais (ABNT NBR 15.575, 2013). Essa norma, apesar de ser destinada a edifícios residenciais serve de referência para outros segmentos, como o hospitalar.

Para tanto, foram feitas pesquisas bibliográficas a respeito do processo de projeto e sua gestão, considerando tanto o edifício como o sistema de fachada. Também foi realizado um estudo de caso, que consistiu na análise do processo de projeto de um edifício hospitalar, feito por meio da analise de documentos, entrevistas com agentes do processo e visitas à obra para observação da execução.

\section{CONTEXTUALIZAÇÃo GERAL E PRINCIPAIS CARACTERÍSTICAS DA FACHADA DO ESTUDO DE CASO}

O empreendimento, objeto do estudo de caso, consiste em um hospital, composto por cinco edifícios, cujo projeto iniciou-se em 2000, a ser complementado e executado por etapas. Apenas um dos edifícios foi construído nesta época. A execução dos demais edifícios foi iniciada apenas após alguns anos, em 2012, quando foram contratados revisões e detalhamento dos projetos. Será objeto de estudo o projeto e a construção do edifício C, reelaborado nesta ocasião, devido ao processo de aprovação legal e às mudanças solicitadas pelo cliente.

A fachada deste empreendimento tem um papel significativo quanto à estética, além de estabelecer relação com as premissas para certificação ambiental e de acústica, e de ter interface com outras disciplinas de projeto, como: Arquitetura, Estrutura (metálica e de concreto), instalações, Climatização, e vedações internas.

A vedação externa do edifício $C$, em quase toda sua extensão, é constituída por uma parede dupla: alvenaria de bloco de concreto de $14 \mathrm{~cm}$ e drywall interno, para passagem das instalações. Sobre a alvenaria, nas faces norte, sul 
e oeste, a fachada recebe painéis unitizados que combinam grandes áreas envidraçadas com trechos opacos em ACM, pedra ou cerâmica. A fachada leste (circulação entre edifícios), por sua vez, tem caixilharia em alumínio e revestimento cerâmico não aderido (fixado por insertes metálicos).

As esquadrias são, em geral, formadas por perfis de alumínio anodizado e painéis de vidro colados com Silicone estrutural monocomponente de cura neutra (sistema conhecido como Structural Glazing). Em todas as fachadas são usados também painéis de alumínio composto (ACM), para cumprir diversas funções, como: máscara sobre a pele de vidro, revestimento da marquise e volumes ocultando instalações sobrepostas à fachada. E na altura do rodapé, são utilizadas placas de rocha fixadas à subestrutura da pele de vidro, ou insertadas diretamente na alvenaria (Fachada Leste).

\section{ANÁLISE DAS NÃO CONFORMIDADES IDENTIFICADAS DURANTE A EXECUÇÃO DA FACHADA}

Em razão das entrevistas com agentes do processo de produção da fachada do hospital e das visitas feitas à obra, foi possível identificar algumas não conformidades na execução dessa fachada, aquelas mais recorrentes e representativas são descritas e analisadas a seguir.

\subsection{Elementos de fixação das tecnologias de fachada}

Alguns montantes verticais apresentavam cortes, alterando sua seção transversal, em razão da incompatibilidade de posição entre a estrutura metálica principal e a subestrutura da fachada (Figura 1).

A necessidade de ajustes em obra é revelada também pelas sucessivas furações observadas em cantoneiras ou perfis (Figura 2), alterando, às vezes, a posição da fixação e gerando uma excentricidade da carga da fachada aplicada na estrutura do edifício.

Outro aspecto importante em relação à subestrutura é que não foi previsto acesso para manutenção. Desde já, há sinais de corrosão em alguns pontos, que não poderão ser inspecionados. Por exemplo, os arames utilizados para auxiliar na fixação da placa de rocha a subestrutura, que ficaram presos ao silicone e sofreram corrosão galvânica (Figura 3, Figura 4), ao que tudo indica, causando manchas no revestimento. 
Figura 1 -

Subestrutura $X$ Estrutura metálica

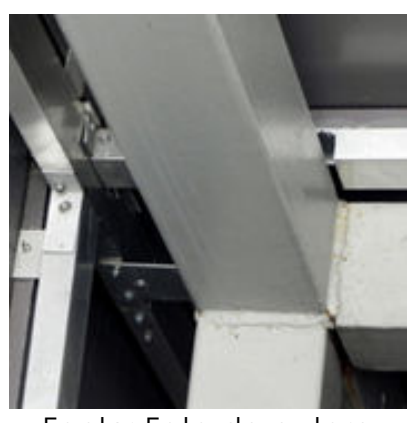

Fonte: Foto da autora
Figura 2 -

Furações no perfil da fachada

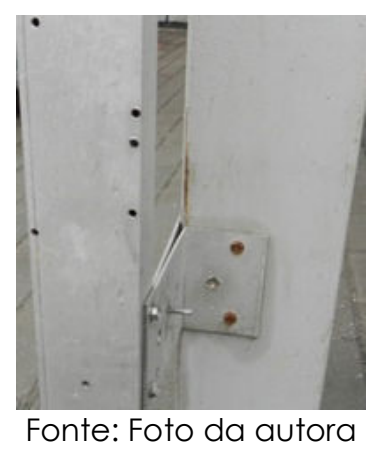

Figura 3 - Arame Figura 4 - Mancha para amarração temporária na pedra (corrosão metálica)
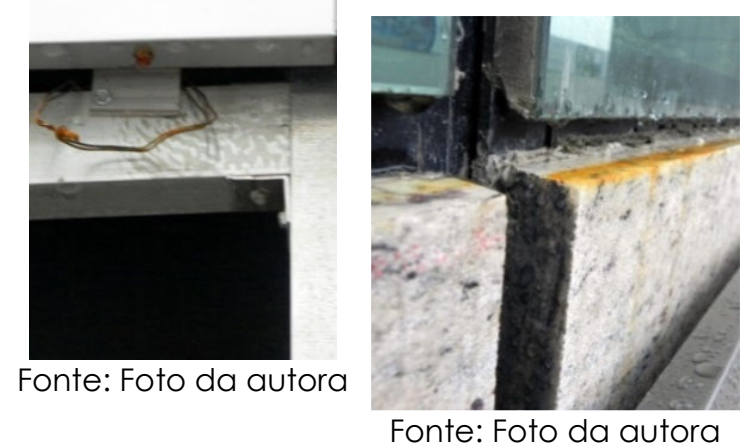

\subsection{Substrato (alvenaria)}

Há pontos onde foram feitas aberturas para fixação de ancoragens e, posteriormente, fechadas com material de base cimentícia, por conta de alteração ou incompatibilidade de projeto (Figura $5,6,7)$. A resistência e aderência inadequadas do material utilizado na reparação podem vir a comprometer a fixação do sistema de fachada.

Figura 5 - Fixação da esquadria

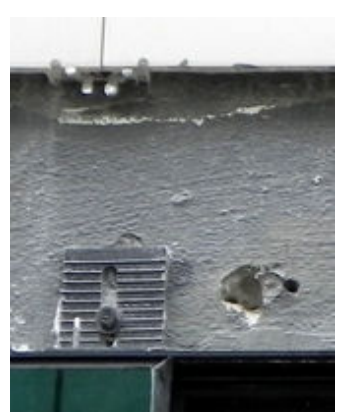

Fonte: Foto da autora
Figura 6 - Fixação da subestrutura da fachada

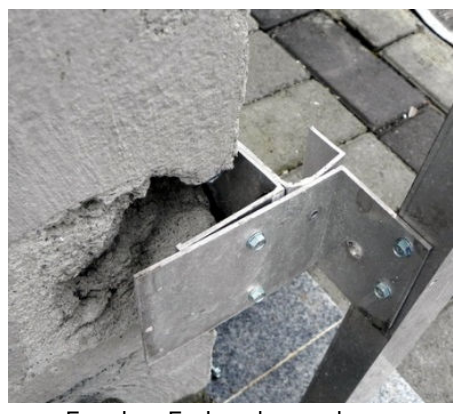

Fonte: Foto da autora
Figura 7 - Fixação da esquadria

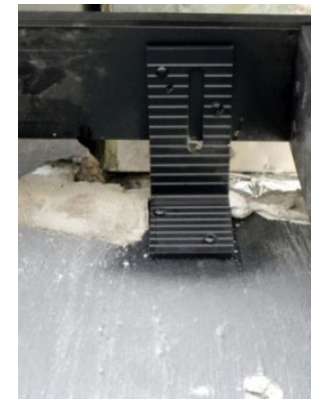

Fonte: Foto da autora

\subsection{Vãos: Interface entre vedação e esquadrias}

A posição dos vãos foi a consequência mais evidente dos conflitos gerados pelas revisões tardias do projeto e a dificuldade da obra em acompanhá-las. A maioria dos vãos na alvenaria apresentava posição defasada em relação à caixilharia - de até $20 \mathrm{~cm}$. Foram usados artifícios para ocultar estes erros, tais como molduras internas (Figura 8). 
Figura 8 Arremate interno

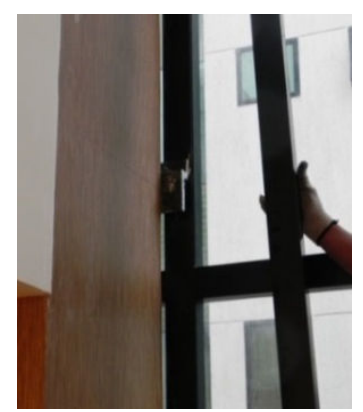

Fonte: Foto da autora
Figura 9 -

Ausência de arremate

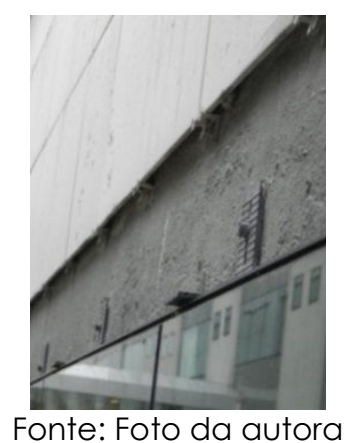

Figura 10 -

Frestas

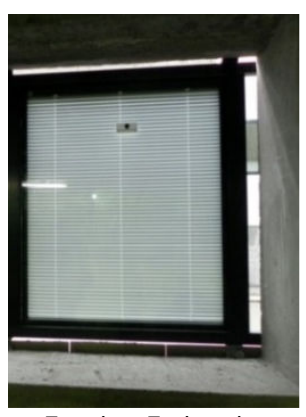

Fonte: Foto da autora
Figura 11 frestas na esquadria

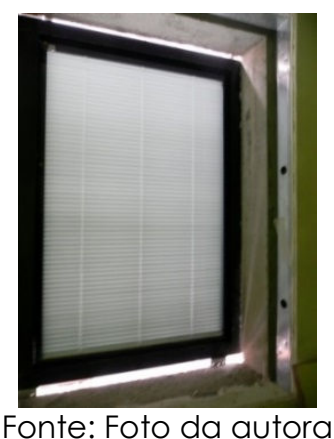

$\mathrm{Na}$ fachada revestida em porcelanato, o projeto não propôs solução específica para o arremate das esquadrias - interface entre vedação e esquadria (Figura 9, 10), que permanecia ainda aberta até a data da visita técnica. A falta de estanqueidade, durante a obra, pode ter deteriorado elementos internos, como o drywall que eventualmente recebeu chuva ao longo do período exposto (Figura 11).

\subsection{Juntas entre placas de vidro, ACM e placas de rocha}

A eficiência das juntas na pele de vidro é um ponto deficitário desde a especificação em projeto no caso estudado: não foram especificadas suas dimensões e tampouco estabelecidas tolerâncias para aceitação. Nota-se, em toda a extensão da fachada, muita variação na largura destas juntas, especialmente na transição entre componentes de diferentes materiais, como ACM e vidro; ou entre estes a as placas de rocha (Figuras 12, 13).

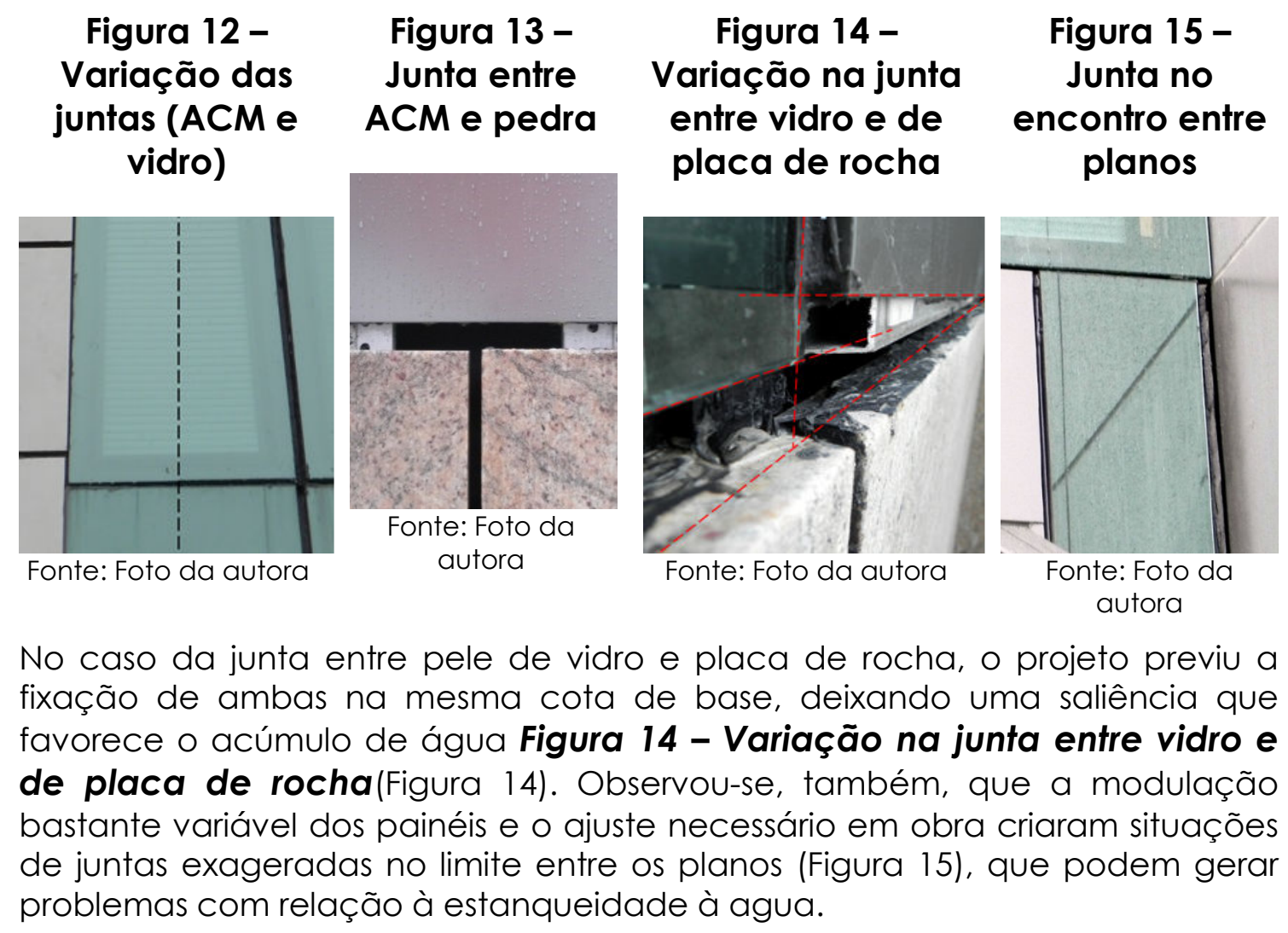




\subsection{Componentes de fechamento}

De acordo com o Arquiteto da construtora - responsável pela contratação e coordenação da execução da fachada - em algumas faces, a quebra de vidros chegou a $30 \%$ da área. A substituição de peças pôde ser notada pela presença de fixações temporárias (band-aids - Figura 16), além dos vidros ainda fissurados (Figura 17). As hipóteses acerca da razão desta ocorrência combinam más condições de armazenagem em obra a esforços de movimentação do sistema (juntas inadequadas). Há componentes de fechamento faltantes por indefinição de projeto, por exemplo, os trechos ortogonais ao plano da fachada, fruto das pequenas variações volumétricas (Figuras 20, 21), que não foram detalhados. Após a instalação dos panos principais da fachada, estes trechos foram medidos para a posterior fabricação dos componentes.

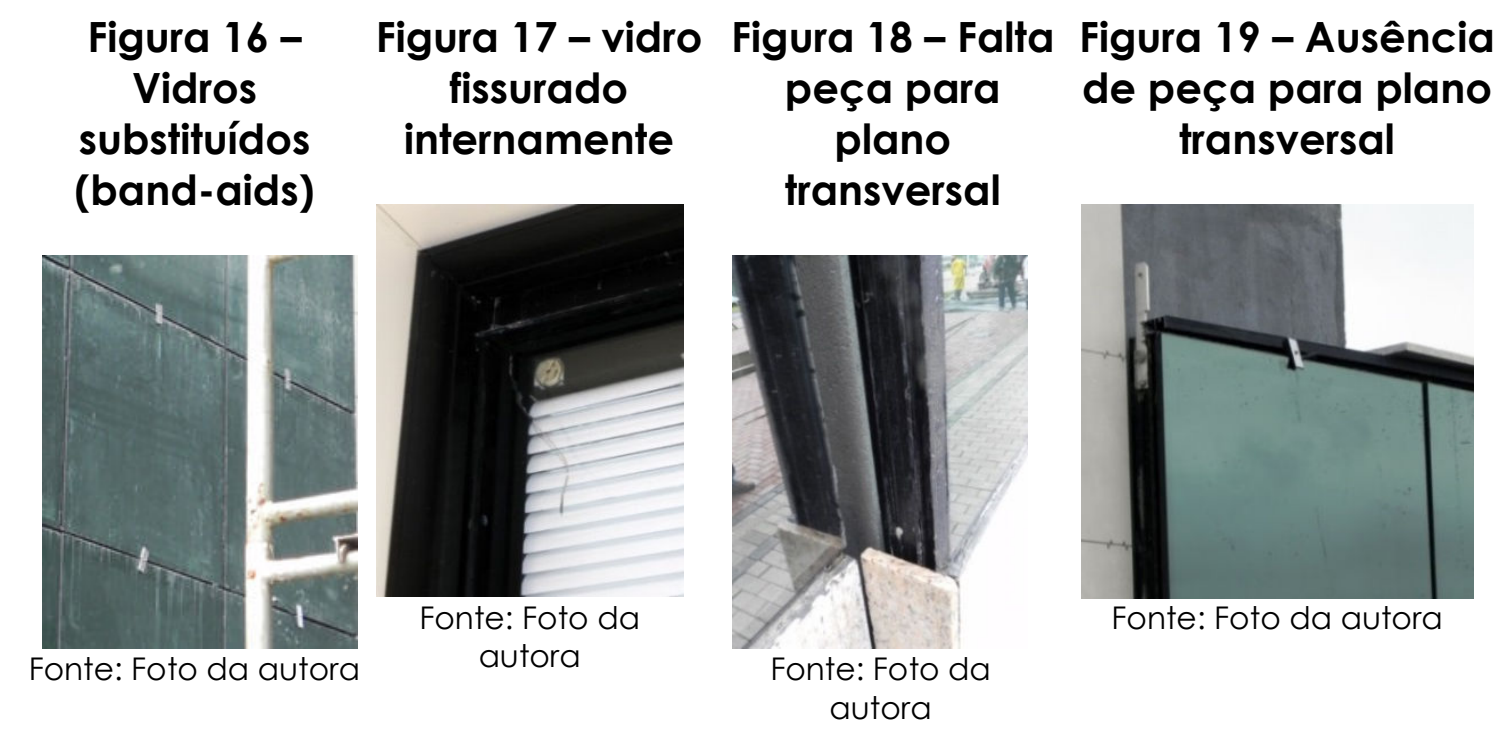

\section{ANÁLISE DO PROCESSO DE PROJETO}

O edifício em questão teve sua inauguração prevista para um ano e meio após a data de retomada dos projetos, no início de 2012, mas a entrega da obra já apresentava um atraso de 20 meses na ocasião da elaboração deste artigo. Ao analisar este atraso, encontram-se diferentes razões, sendo muitas delas relacionadas à entrega tardia da versão final dos projetos e ao número de revisões que estes sofreram. Segundo Atkinson, Crawford e Ward (2006), alterações de projeto representam uma causa recorrente de impactos no prazo, custo e qualidade das construções, especialmente quando introduzidas sem prévia verificação de suas interfaces.

O edifício teve um aumento de altura aprovado junto aos órgãos legais e sua estrutura original demolida para adequação. Quando da definição da necessidade de um novo projeto, este foi elaborado pela equipe de Arquitetura - identificada neste texto por Arquitetura (1) - com orientação direta do cliente.

Com a primeira versão da estrutura e da arquitetura, a execução iniciou-se antes da emissão inicial das demais disciplinas de projeto e sem uma análise do impacto que isso causaria na obra. De acordo com Laufer, Denker e 
Shenhar (1996), o avanço de etapa, sem isolar incertezas, causa retrabalho na fase de execução, como no caso estudado.

Com a pressão do cliente pelo cumprimento de prazo, foi necessário retomar a obra logo na sequência da demolição da estrutura inicial (Figura 20). Assim, a validação dos produtos para transição de etapas foi suprimida e a análise de soluções para interfaces entre disciplinas foi reduzida. Para Atkinson, Crawford e Ward (2006), tal imposição de prazo pelos empreendedores, por vezes impraticáveis, geram definições prematuras de projeto, com consequências para o andamento da obra, conforme explicitado no item 3.

Figura 20 - Sequência do desenvolvimento dos temas no processo

\section{estudado}

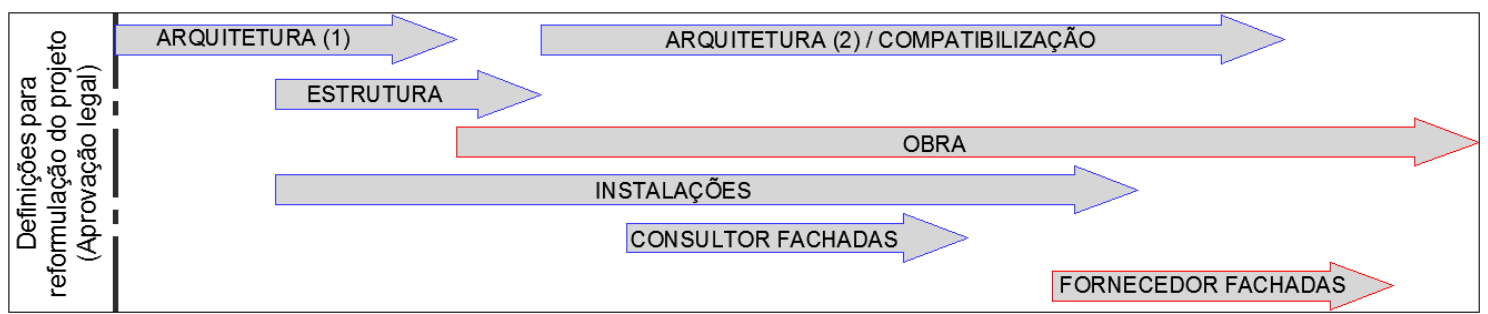

Fonte: Elaborada pela autora

A obra já estava iniciada, quando a Arquitetura (1) foi substituída e algumas funções redefinidas. O cliente era representado por um departamento de engenharia interno, que devia validar a liberação das etapas, e ao Arquiteto (2) coube a compatibilização geométrica. Contudo, nenhum destes agentes assumiu a completa coordenação do projeto. Segundo Nóbrega Junior e Melhado (2013), o coordenador de projetos é responsável por garantir a compatibilidade entre as soluções de projeto e destas com o produto concebido pelo empreendedor, buscar o feedback da obra e alinhar o projeto com estas solicitações. No presente estudo de caso, a ausência desta figura tornou-se evidente pela recorrência de falhas no processo de projeto.

A partir da arquitetura pré-compatibilizada com as disciplinas já emitidas, foi elaborado o projeto específico de fachada. O projeto foi desenvolvido sem que antes fosse feita uma análise crítica da concepção inicial, por exemplo, questionando o uso do sistema unitizado para esta fachada. Os principais benefícios desta tecnologia são a alta produtividade e a facilidade de controle de qualidade. No caso estudado, a fachada apresenta uma grande variedade de painéis, com dimensões e padrões diferentes, e é composta em planos variados, criando detalhes de difícil execução. De acordo com a reportagem da Téchne (2003), painéis unitizados não apresentam uma boa relação custo benefício nos casos em que a modulação é muito recortada ou de pequenas dimensões. Além disso, a fachada estudada sofreu diversas alterações, exigindo ajustes em obra; o que, de acordo com Medeiros et al. (2014), não é simples e pode onerar este sistema.

A versão final do projeto produzido pelo especialista em fachada não acompanhou as revisões gerais. Por questões contratuais, associadas às alterações tardias na arquitetura, o projeto específico de fachada foi encerrado sem todos os detalhes e especificações necessários. O projeto de fachada não continha memorial descritivo, e seu detalhamento foi omisso em vários aspectos: não contemplou situações específicas (encontros, mudanças 
de planos), não fez uma análise crítica e da modulação, não dimensionou os insertes e as juntas, não estabeleceu parâmetros de aceitação em obra e, tampouco, premissas de desempenho.

Tomando como referência o processo de projeto para fachada leve, proposto por Oliveira (2009), é possível observar a supressão de algumas informações nas etapas iniciais do projeto neste estudo de caso. Isso acelerou o processo de concepção, gerando, contudo, prejuízo ao produto desta fase.

Conscientes da frequente necessidade de alterações durante o processo, Hansen e Olsson (2011) defendem a importância da flexibilidade no projeto para viabilizar inovações, destacando, contudo, que é vantajosa nas fases iniciais, quando as alterações geram pouco retrabalho. Neste estudo de caso, a etapa mais propícia para introdução de alterações e redefinição de conceitos foi reduzida. Fazendo com que esta necessidade aflorasse posteriormente, com os projetos desenvolvidos e a execução já iniciada.

Observa-se, também, como falha neste processo, a ausência de interação entre os agentes. Tribelsky e Sacks (2011) constataram, uma qualidade superior do projeto quando elaborado por equipes com um fluxo contínuo e controlado de informações. No presente estudo de caso, foram analisadas as datas e justificativas das revisões das principais disciplinas que interferem diretamente na fachada e observou-se a demora de cada disciplina em assimilar as demais e o envio de informações conflitantes para a obra. Para Vedovello (2012), o sucesso no uso do sistema de painéis unitizados depende da análise e validação dos projetos de fabricação e montagem, e da compatibilização destes com as demais disciplinas. Ou seja, a falta de uma coordenação presente, acabou por comprometer o andamento e a qualidade da execução do edifício.

A qualidade do projeto tem impacto no processo construtivo e nas etapas de uso e ocupação do edifício. Olsson (2006) aponta a flexibilidade como um importante instrumento de planejamento e defende a capacidade de adiar decisões ou aumentar sua maleabilidade até que se tenham mais informações, permitindo mais segurança na definição de um assunto. Por isso, em casos onde não há informação suficiente para a tomada de decisão inicial, ou quando é preciso avançar a etapa sem as soluções desejáveis, fazse necessário um planejamento que contemple estas pendências, o impacto disto nas próximas fases e nas demais disciplinas.

No entanto, a transição brusca entre etapas sem sua conclusão ou preparação para as fases subsequentes, somada ao trabalho isolado dos agentes ligados à fachada, deixou pendentes questões importantes para a execução e o desempenho deste subsistema.

\section{IMPACTO DAS FALHAS LEVANTADAS}

A partir da análise do processo de projeto da fachada do estudo de caso e das não conformidades identificadas na sua execução, foi elaborado o Quadro 1, que sintetiza as falhas com origens prováveis no projeto e seus impactos no desempenho e na execução. As falhas no projeto podem ter sido agravadas por ocorrências de obra, mas estas não foram objeto deste estudo.

Do ponto de vista estético, a incompatibilidade entre disciplinas ao longo do processo teve implicação na aparência de alguns trechos da fachada, assim como a solução improvisada para encontros entre componentes, a variação 
exagerada entre juntas, o desalinhamento dos vãos e as manchas de umidade nas placas de rocha.

Em decorrência da falta do detalhamento adequado, observou-se a improvisação de soluções em obra e a má execução de interfaces entre componentes, comprometendo a estanqueidade a água do sistema de fachada.

\section{Quadro 1 - Falhas na execução da fachada e prováveis impactos no desempenho}

\begin{tabular}{|c|c|c|c|}
\hline Elemento & Falha & $\begin{array}{l}\text { Impactos no desempenho } \\
\text { (Risco de ocorrer) }\end{array}$ & $\begin{array}{l}\text { Impactos na } \\
\text { execução }\end{array}$ \\
\hline \multirow{3}{*}{$\begin{array}{l}\text { Elementos } \\
\text { de Fixação } \\
\text { (insertes / } \\
\text { subestrutura) }\end{array}$} & $\begin{array}{l}\text { Não há como } \\
\text { inspecionar }\end{array}$ & $\begin{array}{l}\text { Não tem potencial para } \\
\text { atender aos requisitos de } \\
\text { manutenibilidade }\end{array}$ & - \\
\hline & $\begin{array}{c}\text { Corte dos } \\
\text { montantes/ } \\
\text { Extensão dos } \\
\text { insertes/ } \\
\text { Furações } \\
\text { excessivas }\end{array}$ & $\begin{array}{l}\text { Risco de afetar a } \\
\text { resistência mecânica e } \\
\text { estabilidade da } \\
\text { subestrutura da fachada }\end{array}$ & $\begin{array}{l}\text { Trabalho artesanal: } \\
\text { Prejuízo de Prazo, } \\
\text { Custo e Qualidade }\end{array}$ \\
\hline & Corrosão & $\begin{array}{l}\text { Comprometimento da } \\
\text { durabilidade dos } \\
\text { componentes de fixação }\end{array}$ & - \\
\hline Substrato & $\begin{array}{c}\text { Cicatrizes de } \\
\text { intervenção } \\
\text { (furações corrigidas } \\
\text { com massa) }\end{array}$ & $\begin{array}{c}\text { Risco de gerar } \\
\text { desestabilidade, em razão } \\
\text { de falhas de resistência } \\
\text { mecânica e } \\
\text { desagregação do } \\
\text { substrato }\end{array}$ & $\begin{array}{c}\text { Retrabalho } \\
\text { (alteração na } \\
\text { posição de fixação) }\end{array}$ \\
\hline Vãos & $\begin{array}{c}\text { Vãos da caixilharia } \\
\text { desalinhados do } \\
\text { substrato } \\
\text { (carenagem) }\end{array}$ & $\begin{array}{l}\text { Comprometimento da } \\
\text { Estética e da } \\
\text { estanqueidade à agua/ } \\
\text { Perda da área visual nos } \\
\text { ambientes }\end{array}$ & $\begin{array}{l}\text { Solução em obra e } \\
\text { produção posterior: } \\
\text { Prejuízo de prazo }\end{array}$ \\
\hline Esquadria & $\begin{array}{c}\text { Frestas/ } \\
\text { inacabadas }\end{array}$ & $\begin{array}{l}\text { Comprometimento da } \\
\text { estanqueidade }\end{array}$ & $\begin{array}{l}\text { Solução em obra: } \\
\text { prejuízo de Prazo }\end{array}$ \\
\hline Juntas & $\begin{array}{l}\text { Irregularidade nas } \\
\text { dimensões das } \\
\text { juntas }\end{array}$ & $\begin{array}{c}\text { Durabilidade, } \\
\text { estanqueidade à água e } \\
\text { estético (visual/ fissuração } \\
\text { ou empenamento do } \\
\text { fechamento) }\end{array}$ & $\begin{array}{c}\text { Dificuldade na } \\
\text { aplicação do selante } \\
\text { nas juntas/ Peças } \\
\text { substituídas }\end{array}$ \\
\hline \multirow{3}{*}{$\begin{array}{l}\text { Component } \\
\text { es de } \\
\text { Fechament } \\
\text { o }\end{array}$} & \begin{tabular}{|c|} 
Ausência de painel \\
de fechamento \\
(faces ortogonais)
\end{tabular} & $\begin{array}{l}\text { Comprometimento da } \\
\text { estanqueidade e estética }\end{array}$ & $\begin{array}{l}\text { Solução em obra e } \\
\text { produção posterior: } \\
\text { Prejuízo de prazo }\end{array}$ \\
\hline & $\begin{array}{l}\text { Revestimento } \\
\text { pétreo saliente } \\
\text { (acumula água) }\end{array}$ & $\begin{array}{c}\text { Durabilidade: } \\
\text { manchamento das placas } \\
\text { de rocha }\end{array}$ & - \\
\hline & Fissuras (vidro) & $\begin{array}{l}\text { Comprometimento da } \\
\text { estanqueidade e estética }\end{array}$ & $\begin{array}{l}\text { Custo (substituiçãa)// } \\
\text { Prazo/ Geração de } \\
\text { Resíduos }\end{array}$ \\
\hline
\end{tabular}

Fonte: Adaptado pela autora com base em modelo de Rodrigues, Teixeira e Cardoso (2011) 
Para a segurança estrutural, Oliveira (2009) define, a partir de critérios de norma, os requisitos para cada componente: dos dispositivos de fixação, espera-se resistência mecânica e capacidade de absorver ajustes dimensionais na obra. Por exemplo, os cortes inadequados nos perfis e a excentricidade gerada pela alteração na posição das fixações e do afastamento podem ter comprometido o desempenho estrutural.

Galbusera, Brito e Silva (2014) destacam a relevância dos aspectos de projeto e execução do sistema para a vida útil do edifício e suas partes, citando que falhas nestes processos podem reduzir para menos da metade a durabilidade do sistema. Embora a vida útil de projeto não tenha sido estabelecida pelo empreendedor e não haja manual de uso e manutenção disponível até o momento desta pesquisa, algumas considerações podem ser feitas acerca da durabilidade, especialmente dos componentes.

As juntas entre componentes de fechamento, sem definição em projeto, são pontos críticos, uma vez que a sua dimensão e preenchimento são primordiais para o desempenho do sistema. "O desempenho das juntas é fundamental para garantir a segurança estrutural, estanqueidade a água e ao ar, isolamento termoacústico, resistência ao fogo e durabilidade do elemento de fachada" (OLIVEIRA e MELHADO, 2009).

Os componentes de fixação já mostram sinais de comprometimento. Além disso, não há qualquer previsão de acesso para inspeção na fachada, dificultando manutenções futuras e o conhecimento prévio de processos de deterioração eventualmente presentes nos componentes ocultos do sistema. Os indícios de patologia já presentes, somados à impossibilidade de inspeção, expõe o sistema de fachada ao risco de uma falência precoce e da necessidade de intervenções custosas.

Além de questões relacionadas ao desempenho e manutenção do edifício, vale ressaltar que houve implicações no prazo e no custo inicial da construção. Muitas vezes, a fim de evitar um comprometimento maior do desempenho da construção, as soluções são revistas em obra para atenderem ao critério de aceitação do cliente, mas com prejuízos significativos quanto ao prazo e custo. De acordo com Atkinson, Crawford e Ward (2006), o custo, o prazo e o desempenho da construção sofrem o impacto da dificuldade de manter-se a fidelidade entre produto e etapa planejada; em consequência do início da obra sem as definições necessárias de projeto.

\section{CONCLUSÃO}

As não conformidades identificadas no processo de construção da fachada do edifício, objeto do estudo de caso, remetem a diversas razões, dentre elas: falhas no fluxo de informação do processo de projeto, e deste para obra; falhas de especificação e de compatibilidade; falhas no planejamento das atividades de projeto e de obra; e falhas no controle de qualidade da execução.

Houve uma série de alterações em projeto, além de omissões, que interferiram em atividades já iniciadas. Improvisos na obra e soluções de canteiro foram frequentes. Além do impacto em prazo, isto influenciou na qualidade e no potencial desempenho do sistema de fachada, o que possivelmente ocasionará um alto custo de manutenção ao longo da vida útil do edifício. 
Algumas medidas poderiam ter sido tomadas a fim de mitigar os impactos das alterações de projeto e do processo truncado na obra. A primeira delas seria a contratação de um coordenador para planejar e controlar as atividades. A partir de então, a concepção da fachada poderia ter a solução tecnológica reavaliada, a nova volumetria revista e o conjunto submetido à validação pelos agentes envolvidos. Uma compatibilização oportuna e um detalhamento mais completo evitariam a maior parte das revisões na fachada.

E, ainda, uma análise de riscos ajudaria a balizar a tomada de decisão para liberação de frentes de trabalho para obra, procurando afastar incertezas e reduzir o retrabalho. Com o início das atividades direcionado pelo coordenador, haveria mais tempo para a solução dos detalhes em projeto. $\bigcirc$ impacto de alterações tardias de projeto na obra e no desempenho pode ser reduzido com um investimento maior nas definições iniciais e um planejamento mais atento aos conflitos potenciais e às necessidades de detalhamento.

\section{REFERÊNCIAS}

ATKINSON, R., CRAWFORD, L., WARD, S. Fundamental uncertainties in projects and the scope of project management. International Journal Of Project Management, v. 24, n. 8, p.687-698, 2006.

BEASLEY, Kimball J. Latent Building Facade Failures. Forensic Engineering 2012, American Society of Civil Engineers, p.918-927, nov. 2012.

GALBUSERA, M. M., BRITO, J. D., SILVA, A. The importance of the quality of sampling in service life prediction. Construction And Building Materials, v. 66, p.19-29, 2014.

HANSEN, G. K., OLSSON, N. O. E.. Layered Project-Layered Process: Lean Thinking and Flexible Solutions. Architectural Engineering And Design Management, v. 7, p.70-84, 2011.

LAUFER, A., DENKER, G. R., SHENHAR, A. J.. Simultaneous management: the key to excellence in capital projects. International. Journal Of Project Management, v. 14, n. 4, p.189-199, 1996.

MEDEIROS, J. S. et al. Tecnologias de vedação e revestimento para fachadas. Série Manual de Construção em Aço. Rio de Janeiro: Instituto do Aço Brasil / CBCA, 2014.

MÓDULOS rápidos. Téchne, São Paulo, v. 191, 2003. Disponível em: <http://techne.pini.com.br/engenharia-civil/191/artigo288022-3>. Acesso em: 07 ago. 2014.

NÓBREGA JUNIOR, C. L., MELHADO, S. B. Coordenador de projetos de edificações: estudo e proposta para perfil, atividades e autonomia. São Paulo: EPUSP, 2013. 227p..

OLIVEIRA, L. A. Metodologia para desenvolvimento de projetos de fachadas leves. 2009. 267f. Tese (Doutorado em Engenharia Civil) - Escola Politécnica da Universidade de São Paulo, São Paulo.

OLIVEIRA, L. A., MELHADO, S. B. Projeto de fachadas leves: especificações de desempenho. Pós, São Paulo, v. 16, n. 25, p.272-290, jun. 2009

OLSSON, N. O. E. Management of flexibility in projects. International Journal Of Project Management, v. 24, n. 1, p.66-74, jan. 2006. 
RODRIGUES, M. F., TEIXEIRA, J. M. C., CARDOSO, J. C. P. Buildings' Envelope Anomalies: a Visual Survey Methodology. Construction And Building Materials, v. 25, n. 5, p.2741-50, 2011.

TRIBELSKY, E. I., SACKS, R. An Empirical Study of Information Flows in Multidisciplinary Civil Engineering Design Teams using Lean Measures. Architectural Engineering And Design Management, v. 7, n. 2, p.85$101,2011$.

VEDOVELLO, C. A. da S. Gestão de projetos de fachadas. 2012. 406 f. Dissertação (Mestrado em Engenharia) - Escola Politécnica de Engenharia da Universidade de São Paulo, São Paulo, 2012.

WILLIAMS JUNIOR, C. E., JOHNSON, P. W. Inadequate Design Management Compared with Unprecedented Technical Issues as Causes for Engineering Failure. Journal Of Performance Of Constructed Facilities, v. 29, n. 1, Feb, 2015. 